\title{
Associations between body mass index and severity of psoriasis
}

This article was published in the following Dove Press journal:

Clinical, Cosmetic and Investigational Dermatology

Number of times this article has been viewed

\author{
Mohammadreza Sobhan \\ Mahmoud Farshchian \\ Psoriasis Research Center, \\ Department of Dermatology, \\ Farshchian Hospital, Hamadan \\ University of Medical Sciences, \\ Hamadan, Iran
}

Correspondence: Mohammadreza Sobhan Psoriasis Research Center, Department of Dermatology, Farshchian Hospital, Hamadan University of Medical Sciences, Mirzade Eshghy Street, 65I6840874I Hamadan, Iran

Tel +989121089455

Emailmreza_sobhan@yahoo.com
Objective: Compared with healthy people, overweight and obesity are more commonly found among those suffering from skin conditions such as psoriasis. The present study was an attempt to survey the relationship between obesity and intensity of psoriasis.

Patients and methods: A total of 42 patients with psoriasis who were referred to Farshchian Hospital, Hamadan, participated in this cross-sectional descriptive-analytical study. Patients were classified into mild, moderate and severe based on the intensity of the disease measured by Psoriasis Area and Severity Index (PASI). Body mass index (BMI), waist size, age, gender, smoking and drinking habits of the participants were measured and compared.

Results: A total of 15 (35.07\%) patients had mild psoriasis, 9 (21.4\%) patients had moderate psoriasis and $18(42.9 \%)$ patients suffered from severe psoriasis. Mean BMI of mild psoriasis patients was $25.86 \pm 5.93 \mathrm{~kg} / \mathrm{m}^{2}$, and this figure for the moderate and severe psoriasis patients was $30.85 \pm 3.77 \mathrm{~kg} / \mathrm{m}^{2}$ and $26.96 \pm 5.68 \mathrm{~kg} / \mathrm{m}^{2}$, respectively $(P=0.096)$. Mean waist size of the mild psoriasis patients was $91.54 \pm 11.49 \mathrm{~cm}$, and for moderate and severe patients, it was $99 \pm 8.39 \mathrm{~cm}$ and $92.17 \pm 10.73 \mathrm{~cm}$, respectively $(P=0.211)$.

Conclusion: The results of this study showed no significant difference between mean value of body mass index, waist size, age and gender in mild, moderate and severe groups of the psoriasis patients.

Keywords: psoriasis, body mass index, PASI measure

\section{Introduction}

Psoriasis is a chronic disease that is related to the immune system. It is caused by a polygenetic trait along with environmental factors such as trauma, infection or drugs. Underlying pathophysiology affects $T$ cells and their interaction with dendritic cells and the cells dealing with innate immunity such as keratinocytes. ${ }^{1-3}$ Psoriasis is a common disease, and there are reports of $2 \%-4.7 \%{ }^{2,4}$ outbreak rates of the disease. However, there is a lack of specific data about the prevalence of the disease, with the majority of studies reporting estimates only. ${ }^{2}$ It affects patients at different ages; meanwhile, it is more common at two age ranges of $20-30$ and 50-60 years. ${ }^{1}$ Between $60 \%$ and $90 \%$ of patients with psoriasis have a family history of the disease, making it one of the most heritable diseases known. ${ }^{3}$

Psoriasis causes many side effects, such as influencing physical, mental and professional health of the patient. Indeed, life quality of psoriasis patients is comparable with that of cardiovascular and cancer patients. ${ }^{4,5}$ In particular, $19 \%$ of the psoriasis patients with arthritis suffer from operational inabilities, which tackle their life quality. ${ }^{6}$ 
Body mass index (BMI) nowadays is one of the simplest indices available for measuring the weight-to-height ratio. There are proved evidences regarding the relationship between psoriasis and many diseases pertinent to weight such as diabetes type II, blood pressure, ischemic heart disease (IHD) and hyperlipidemia. Increase in weight among psoriasis patients is probably due to treatment approaches and clinical response of the patient to the systemic disease. Currently, dermatologists put more emphasis on using BMI to examine treatment progress of psoriasis patients, considering that obesity is an independent risk factor for psoriasis. ${ }^{7}$

Obesity may exacerbate the clinical manifestations or even trigger the disease. The relationship between obesity and psoriasis is probably bidirectional, with obesity predisposing patients to psoriasis and psoriasis increasing the risk of obesity. However, the epidemiological evidence currently available is insufficient to establish which comes first, obesity or psoriasis. ${ }^{8}$

There are several parameters to measure the intensity of psoriasis, including the area of body affected by the diseases, activity of disease (redness of plaque, thickness, scaling), response to previous treatment and its effect on one's illness. ${ }^{1,9,10}$

Severity of psoriasis is measured by "Psoriasis Area and Severity Index" (PASI). The index estimates using the affected area of skin by scoring redness, thickness and scaling at each four parts of body (head, trunk, upper limbs and lower limbs) and ranks the severity of disease from 0 (no involvement) to 72 (maximum involvement). ${ }^{11}$

Determining the risk factors of the disease can help to control the disease, lead to less drug consumption and improve the disease. As noted, overweighting is one of the effective factors of the psoriasis disease that has triggered great deal of research works. Relationship between weight and severity of psoriasis is not proven yet, and it is an area of ongoing studies.

\section{Patients and methods}

The present study was carried out as a descriptive-analytic cross-sectional work. The institutional review board of Hamadan University of Medical Sciences approved the research. The study population comprised all psoriasis patients referred to Farshchian Hospital, Hamadan, between March 2014 and March 2015.

Criteria for removing a patient from the study were as follows:

1. reluctance to take part in the study;

2. history of familial hyperlipidemia, diabetes and hypothyroid disorder and
3. history of taking topical psoriasis therapies from 1 month prior to and intake of systemic drugs from 6 months before the onset of the study.

Participants were selected using convenience sampling. After the study had been fully described to 42 patients who met the participation criteria, written informed consent was obtained from each patient. They were examined accurately, and clinical and demographical information was recorded in a checklist. The recorded information included age, gender, type of symptoms and severity of involvement of the patient.

PASI was measured by the dermatologist, and BMI was calculated by dividing the patient's weight $(\mathrm{kg})$ by square root of the height $(\mathrm{m})$. The obtained results were interpreted as follows:

- $\mathrm{BMI}<18.5 \mathrm{~kg} / \mathrm{m}^{2}$ : underweight;

- $24.9>\mathrm{BMI}>18.5 \mathrm{~kg} / \mathrm{m}^{2}$ : ideal weight range;

- $29.9>\mathrm{BMI}>25 \mathrm{~kg} / \mathrm{m}^{2}$ : overweight range;

- $30<\mathrm{BMI}<34.9 \mathrm{~kg} / \mathrm{m}^{2}$ : obesity type I;

- $39.9>\mathrm{BMI}>35 \mathrm{~kg} / \mathrm{m}^{2}$ : obesity type II and

- BMI $>40 \mathrm{~kg} / \mathrm{m}^{2}$ : obesity type III (extreme).

All the measurements (weight and height) were taken under fasting condition in the morning using a scale and a ruler; however, self-reports were not taken into account.

A checklist was used to collect demographical, clinical and patients' condition data. The data were analyzed in SPSS (version 16) using the descriptive test, chi-square test, $t$-test and nonparametric tests such as the Mann-Whitney $U$-test if needed.

\section{Results}

The 42 participants were classified based on PASI into three classes: mild psoriasis (0-7), moderate psoriasis (7-12) and severe psoriasis $(>12)$.

In all, $15(35.07 \%)$ patients suffered from mild psoriasis, $9(21.4 \%)$ had moderate psoriasis and 18 (42.9\%) had severe psoriasis (Figure 1).

The average age of the participants was $46 \pm 13.39$ years. In addition, the average age of mild, moderate and severe psoriasis patients was $47.20 \pm 11.36,42.56 \pm 11.93$ and $49.67 \pm 11.07$ years, respectively $(P=0.318)$.

Mean BMI of the participants was $27.4 \pm 5.64 \mathrm{~kg} / \mathrm{m}^{2}$, and this figure for mild, moderate and severe psoriasis patients was $25.86 \pm 5.93 \mathrm{~kg} / \mathrm{m}^{2}, 30.85 \pm 3.77 \mathrm{~kg} / \mathrm{m}^{2}$ and $26.96 \pm 5.68 \mathrm{~kg} / \mathrm{m}^{2}$, respectively $(P=0.096$; Table 1$)$.

Figure 2 illustrates the relationship between BMI and severity of the disease based on PASI. Pearson's correlation test indicated no relationship between BMI and PASI 


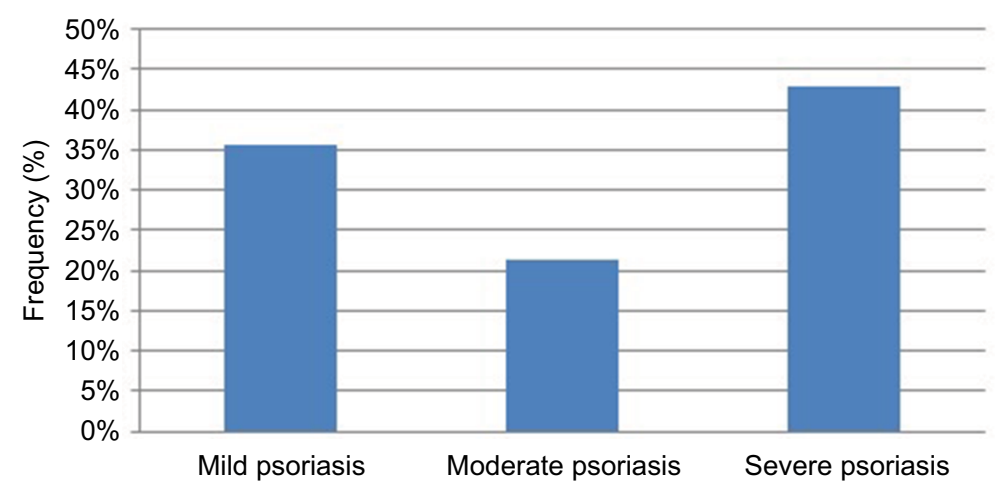

Figure I Frequency of the severity of psoriasis in patients.

Table I Average BMI $\left(\mathrm{kg} / \mathrm{m}^{2}\right)$ in psoriasis patients

\begin{tabular}{lllll}
\hline Group & Mean BMI & SD & Minimum & Maximum \\
\hline Mild psoriasis & 25.86 & 5.93 & 16 & 35 \\
Moderate psoriasis & 30.85 & 3.77 & 26 & 35.3 \\
Severe psoriasis & 26.96 & 5.68 & 17 & 40.1 \\
Total & 27.4 & 5.64 & 16 & 40.1 \\
\hline
\end{tabular}

Abbreviation: BMI, body mass index.

$(P=0.849)$. In addition, the patients on the bases of BMI were classified into six groups: underweight $(n=3,7.1 \%)$, normal weight ( $\mathrm{n}=10,23.8 \%)$, overweight $(\mathrm{n}=13,31 \%)$, obese type $1(\mathrm{n}=11,26.2 \%)$, obese type $2(\mathrm{n}=4,9.5 \%)$ and obese type $3(\mathrm{n}=1,2.4 \% ; P=0.438)$.

Gender distribution of the participants showed that out of 42 patients, $23(54.8 \%)$ were male and $19(45.2 \%)$ were female $(P=0.708)$.

Mean waist size of the patients was $93.4 \pm 10.74 \mathrm{~cm}$, and this figure for mild, moderate and severe psoriasis patients was $91.54 \pm 11.49,99 \pm 8.39$ and $92.17 \pm 10.73$, respectively $(P=0.211$; Table 2).

Mean age of initiation of the disease was $40.095 \pm 9.28$ years. In addition, mean age of initiation of disease for mild, moderate and severe psoriasis patients was $40.34 \pm 8.00$, $37.66 \pm 9.84$ and $41.12 \pm 9.55$ years, respectively $(P=0.667)$.

Mean period of the disease was $7.12 \pm 2.89$ years. In addition, mean period of the disease for mild, moderate and severe psoriasis patients was $6.87 \pm 2.88,4.89 \pm 2.53$ and $8.45 \pm 2.41$, respectively $(P=0.007)$.

Drinking behavior survey showed that $9(21.4 \%)$ patients had a history of using alcoholic drinks and 33 (78.6\%) patients had never used alcoholic drinks $(P=0.510)$.

Smoking habits survey showed that 14 (33.3\%) patients used to smoke or smoked and $28(66.7 \%)$ patients had never smoked $(P=0.760)$.

\section{Discussion}

The main objective of this study was to study the association of obesity with psoriasis severity. Farshchian et al in Hamadan conducted a case-control study about psoriasis, highlighting that BMI of cases $\left(26.36 \pm 4.71 \mathrm{~kg} / \mathrm{m}^{2}\right)$ was significantly $(P=0.02)$ higher than that of controls $\left(24.6 \pm 3 \mathrm{~kg} / \mathrm{m}^{2}\right) .{ }^{12}$

We found that in Hamadan, mean BMI of the mild, moderate and severe psoriasis patients was $25.86 \pm 5.93,30.85 \pm 3.77$ and $26.96 \pm 5.68 \mathrm{~kg} / \mathrm{m}^{2}$, respectively $(P=0.096)$, and no significant difference was found regarding mean BMI. In addition, the results showed no significant difference among the three groups of patients based on BMI and severity of the disease.

Bardazzi et al surveyed the severity of psoriasis and its relationship with BMI in Italy. They found a significant relationship between the increase in BMI and waist size on one side and the increase in the severity of the disease. ${ }^{13}$ Prignano et $\mathrm{al}^{14}$ surveyed 268 psoriasis patients. They showed that, based on PASI, gaining weight was related to response to treatment, which is inconsistent with our results. There are other studies such as Esposito et $\mathrm{al}^{15}$ that found significant difference between PASI scores among the patients with different BMIs in Italy.

Felming et $\mathrm{al}^{16}$ published a systemic review of literature indicating a significant association of increased psoriasis severity with higher BMI in seven of nine articles. Armstrong et al in a meta-analysis of 16 observational studies revealed that the pooled odds ratio (OR) for obesity among patients with psoriasis was 1.66 (95\% confidence interval [CI]: 1.46-1.89) compared with those without psoriasis. Meanwhile, patients with more severe psoriasis are at higher odds of obesity compared with those with mild psoriasis. ${ }^{17}$

Earlier works on the relationship between psoriasis and obesity were performed in Europe by large-scale epidemiological works. ${ }^{18-21}$ 


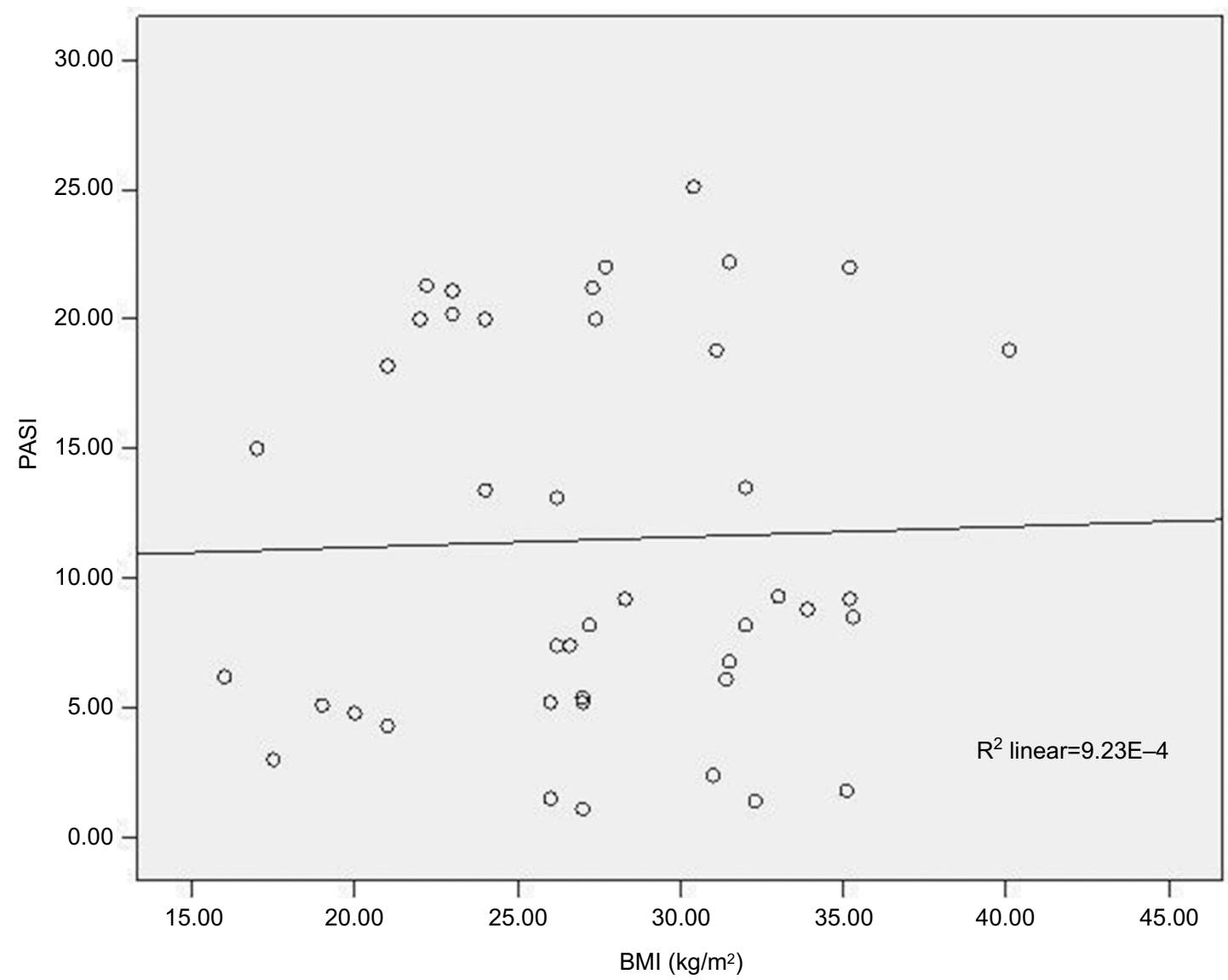

Figure 2 Relationship between BMI and PASI.

Abbreviations: BMI, body mass index; PASI, Psoriasis Area and Severity Index.

Table 2 Average waist size $(\mathrm{cm})$ in patients

\begin{tabular}{lllll}
\hline Group & $\begin{array}{l}\text { Average } \\
\text { waist size }\end{array}$ & SD & Minimum & Maximum \\
\hline Mild psoriasis & 91.54 & 11.49 & 70 & 106 \\
Moderate psoriasis & 99 & 8.39 & 90 & 108 \\
Severe psoriasis & 92.17 & 10.73 & 74 & 114 \\
Total & 93.4 & 10.74 & 70 & 114 \\
\hline
\end{tabular}

In 1986, the first study of this type was performed in Scandinavia, and the results showed that obesity is more common among psoriasis female patients. ${ }^{19}$

A primitive study in the USA showed that obesity is more common among psoriasis patients compared with normal population. ${ }^{21}$

Obesity is growing fast in developed and developing countries, and there are comments that obesity influences different skin disorders and increases severity and prevalence of such diseases. ${ }^{21,22}$ This notion is supported by the results of a prospective randomized clinical trial in Denmark, assessing the effect of weight reduction on the severity of psoriasis in overweight patients. After 16 weeks, overweight patients with psoriasis receiving low-energy diet experienced a greater, albeit statistically nonsignificant $(P=0.06)$, decrease in PASI than those in a control group who received routine dietary guidance. ${ }^{23}$

Studies in the past decade have shown chronic inflammation among obese patients, featured with high TNF- $\alpha$, IL6 and CRP level, which in turn is directly related to the increase in BMI. In addition, there are symptoms of change in susceptibility to insulin, higher oxidative stress and generation of free radicals among the obese patients.

Some of the studies have found that inflammatory cytokines might be effective on period and course of psoriasis and its severity, a phenomenon that explains the relationship between BMI and psoriasis. ${ }^{22,24}$

The effect of obesity on the severity of psoriasis was surveyed in our study, and the result showed no significant relationship between the severity of the disease and mean BMI. However, BMI score increases with an increase in the severity of the disease. Mallbris et $\mathrm{al}^{25}$ found no significant difference in BMIs between 200 patients with psoriasis within 12 months of onset and healthy controls. Herron et al 
noted that obesity appears to be the consequence of psoriasis and not a risk factor for the onset of disease. Furthermore, obesity did not positively or negatively affect the response or the adverse effects of topical corticosteroids, light-based treatments and systemic medications. ${ }^{19}$

Mean waist size of the mild psoriasis patents was $91.54 \pm 11.49 \mathrm{~cm}$, and for moderate and severe patients, it was $99 \pm 8.39 \mathrm{~cm}$ and $92.17 \pm 10.73 \mathrm{~cm}$, respectively.

Although waist size increased with higher severity of the disease, no significant difference among the patients was obtained $(P=0.211)$.

Relationship between smoking and drinking habits with severity of the disease was also investigated, and the results showed no significant relationship ( $P$-values of smoking and drinking were 0.76 and 0.510 , respectively). Herron et $\mathrm{al}^{28}$ showed that smoking is more prevalent in obese psoriasis patients compared with obese controls ( $35 \%$ vs $9 \%$; $P<0.001)$.

\section{Conclusion}

The results showed that there was no significant relationship between BMI, waist size, average age and gender means and severity of psoriasis. In addition, there were not enough evidences to accept metabolic syndrome as a risk factor for increasing severity of psoriasis. Although mean BMI and waist size were higher among patients with more severe psoriasis, the difference among the groups of patients was not significant. A small number of participants, probably, explain the lack of significant difference. Surely, more studies in this field will lead to results with higher accuracy.

\section{Disclosure}

The authors report no conflicts of interest in this work.

\section{References}

1. Bolognia JL, Jorizzo JL, Rapini RP. Dermatology. Vol. 1. 3 ed. New York: Mosby; 2012.

2. Christophers E. Psoriasis epidemiology and clinical spectrum. Clin Exp Dermatol. 2001;26:314-320.

3. Young M, Aldredge L, Parker P. Psoriasis for the primary care practitioner. J Am Assoc Nurse Pract. 2017;29(3):157-178.

4. Rapp SR, Feldman SR, Exum ML, Fleischer AB Jr, Reboussin DM. Psoriasis causes as much disability as other major medical diseases. J Am Acad Dermatol. 1999;41(3 Pt 1):401-407.

5. Weiss SC, Kimball AB, Liewehr DJ, Blauvelt A, Turner ML, Emanuel EJ. Quantifying the harmful effect of psoriasis on health-related quality of life. J Am Acad Dermatol. 2002;47(4):512-518.
6. Garg A, Gladman D. Recognizing psoriatic arthritis in the dermatology clinic. J Am Acad Dermatol. 2010;63(5):733-748.

7. Takeshita J, Grewal S, Langan SM, et al. Psoriasis and comorbid diseases: epidemiology. J Am Acad Dermatol. 2017;76(3):377-390.

8. Barrea L, Nappi F, Di Somma C, et al. Environmental risk factors in psoriasis: the point of view of the nutritionist. Int J Environ Res Public Health. 2016;13(7):743.

9. Burns T, Brithnach S, Cox N, Grifiths C. Rook's Textbook of Dermatology. 7th ed. New York: Mosby; 2010.

10. Bhole VM, Choi HK, Burns LC, et al. Differences in body mass index among individuals with PsA, psoriasis, RA and the general population. Rheumatology (Oxford). 2012;51(3):552-556.

11. Schmitt JM, Ford DE. Work limitations and productivity loss are associated with health-related quality of life but not with clinical severity in patients with psoriasis. Dermatology. 2006;213(2):102-110.

12. Farshchian M, Ansar A, Sobhan M. Associations between cardiovascular risk factors and psoriasis in Iran. Clin Cosmet Investig Dermatol. 2015;8:437-442.

13. Bardazzi F, Balestri R, Baldi E, Antonucci A, De Tommaso S, Patrizi A. Correlation between BMI and PASI in patients affected by moderate to severe psoriasis undergoing biological therapy. Dermatol Ther. 2010;23(1):14-19.

14. Prignano F, Ricceri F, Pescitelli L, et al. Comparison of body weight and clinical-parameter changes following the treatment of plaque psoriasis with biological therapies. Curr Med Res Opin. 2009;25(9): 2311-2316.

15. Esposito M, Mazzotta A, Saraceno R, Schipani C, Chimenti S. Influence and variation of the body mass index in patients treated with etanercept for plaque-type psoriasis. Int J Immunopathol Pharmacol. 2009;22(1):219-225.

16. Felming P, Kraft J, Gulliver WP, Lynde C. The relationship of obesity with the severity of psoriasis: a systematic review. J Cutan Med Surg. 2015;19(5):450-456.

17. Armstrong AW, Harskamp CT, Armstrong EJ. The association between psoriasis and obesity: a systematic review and meta-analysis of observational studies. Nutr Diabetes. 2012;2:e54. doi:10.1038/nutd.2012.26.

18. Naldi L, Chatenoud L, Linder D, et al. Cigarette smoking, body mass index, and stressful life events as risk factors for psoriasis: results from an Italian case-control study. J Invest Dermatol. 2005;125(1): 61-67.

19. Herron MD, Hinckley M, Hoffman MS, et al. Impact of obesity and smoking on psoriasis presentation and management. Arch Dermatol. 2005;141(12):1527-1534.

20. Yosipovitch G, DeVore A, Dawn A. Obesity and the skin: skin physiology and skin manifestations of obesity. J Am Acad Dermatol. 2007;56(6):901-916.

21. World Health Organization. Obesity: Preventing and Managing the Global Epidemic. Report of a WHO Consultation on Obesity. Geneva: WHO; 2000.

22. Hamminga EA, van der Lely AJ, Neumann HAM, Thio HB. Chronic inflammation in psoriasis and obesity: implications for therapy. Med Hypotheses. 2006;67(4):768-773.

23. Jensen $\mathrm{P}$, Zachariae $\mathrm{C}$, Christensen R, et al. Effect of weight loss on the severity of psoriasis: a randomized clinical study. JAMA Dermatol. 2013;149(7):795-801.

24. Wakkee M, Thio HB, Prens EP, Sijbrands EJG, Neumann HA. Unfavorable cardiovascular risk profiles in untreated and treated psoriasis patients. Atherosclerosis. 2007;190(1):1-9.

25. Mallbris L, Granath F, Hamsten A, Stahle M. Psoriasis is associated with lipid abnormalities at the onset of skin disease. J Am Acad Dermatol. 2006;54(4):614-621. 


\section{Publish your work in this journal}

Clinical, Cosmetic and Investigational Dermatology is an international, peer-reviewed, open access, online journal that focuses on the latest clinical and experimental research in all aspects of skin disease and cosmetic interventions. This journal is included on PubMed. The manuscript management system is completely online

Submit your manuscript here: https://www.dovepress.com/clinical-cosmetic-and-investigational-dermatology-journal

and includes a very quick and fair peer-review system, which is all easy to use. Visit http://www.dovepress.com/testimonials.php to read real quotes from published authors 